MATEC Web of Conferences 48,05002 (2016)

DOI: $10.1051 /$ matecconf $/ 20164805002$

(C) Owned by the authors, published by EDP Sciences, 2016

\title{
The possibility of distance methods application for snow dump sites monitoring
}

\author{
Olga Pasko ${ }^{1, a}$, Elena Makartsova ${ }^{1}$, Natalia Ushakova ${ }^{1}$, Olga Tokareva ${ }^{1}$ and Mikhail Mochalov ${ }^{2}$ \\ ${ }^{1}$ National Research Tomsk Polytechnic University, 634050 Tomsk, Russia \\ ${ }^{2}$ National Research Tomsk State University, 634050 Tomsk, Russia
}

\begin{abstract}
In this article the results of remote sensing of the Earth for monitoring of four snow dump sites in Tomsk are described. Their compliance with permitted type of the territory use was evaluated. Earlier unknown time of the operation start was identified. The spatial-temporal variability of areas was defined. The temperature profiles of snow dump and background sites were analyzed. Use of remote sensing data allowed easy identification of snow dump sites creation time. The fact that the sites are located out of zones of permitted type of the territory use was revealed, that is violation of the law. For the first time the cartographic material was collected and showed that in the recent years their areas increased in average in $18 \%$. The forecast for the nearest years was made. The article contains satellite images indicting the degradation of soil-vegetative cover of snow dumps. The reasons are contamination and overcooling of the soil in the beginning of vegetation period. The research results became the initial material for perfection of snow dumps territories management and will be applied in the work of environmental protecting service. Approaches proposed by authors may be used in solving similar problems in any region.
\end{abstract}

\section{Introduction}

Efficient management of land resources and making competent managerial decisions in many respects depends on completeness, quality and accessibility of information [1]. Traditional field researches as a rule are time-consuming, expensive, season and time limitations do not allow to obtain the necessary data of the land site conditions before the time of research.

The topical direction of territory conditions monitoring is application of Earth surface Remote Sensing Data (RSD) from the space which are more and more widely used in different fields of research [2]. It allows to define the boarders and square of land areas, their temperature, extent of degradation, environmental risks etc. not only at the moment but in the past time using the space images archive [3].

The objective of this work was revelation of RSD using ability for monitoring of snow dump sites in evaluation of compliance with permitted type of the territory use, spatial-temporal variability of areas and temperature profiles analysis.

The problem of snow dump sites is actual for the most part of Russian regions especially for Western Siberia due to the long period of snow precipitations. In particular in the territory of Tomsk

\footnotetext{
${ }^{a}$ Corresponding author : oap@tpu.ru
} 
city the maximum of snow precipitations is from December until March, the maximum height of snow cover reaches $125 \mathrm{sm}$., and the duration of its occurrence is about half a year [4]. Snow is removed and accumulated on sites arranged for snow dumps. In the time of its melting the accumulated pollutants come to soils (possibly into underground water) and make environmental threat to the plants, animals and health of the population. It should be noted that Tomsk city and regional administrations do not have any information on borders and areas of snow dump sites and time of its operation start. It prevents to the definition of they age, pollutants accumulation level and necessary environmental safety works planning.

\section{Data and methods of research}

Objects of research were territories of four snow dump sites working in Tomsk situated in: Moskovskiy trakt 121 (provisionally CO1), Mostovaya street 40a (CO2), Khromovka settlement 35/2 (CO3), intersection of Ivanovskogo and Visotskogo streets (CO4).

The cartographical, spatial analysis of data and statistical methods of research were used.

For formation of snow dump sites borders and assessment of their areas changes form the time of creation until the current year the satellite images of high spatial resolution of Tomsk area obtained from cartographic service GoogleEarth for the period from 2006 till 2015 were used [5]. The territorial zones where the snow dump sites are situated were analyzed for compliance with permitted type of the territory use by the means of Tomsk urban atlas [6].

Evaluation of snow dump sites and background territories was made on the base of thermal data channel with spatial resolution of $100 \mathrm{~m}$, obtained by the sensor TIRS (The Thermal Infrared Sensor) in the far infrared wavelength range $10.30-11.30 \mu \mathrm{m}$. Calibrated data of the mentioned channel provided by the USA Geological service (USGS) free of charge in the form of images with a radiometric resolution of 16 bits, were recalculated into temperature values in degrees Celsius [7].

Mapping and spatial analysis of data were made by the means of geoinformation systems MapInfo v8.5 and QGIS and software for the Earth remote sensing data processing Erdas imagine v9.2.

\section{Results of research}

The imposition of the coordinates of the snow dumps on the Urban Atlas map [6] allowed to define that snow dump site $\mathrm{CO} 1$ is situated in two territorial zones - social -business zone (sub-zone of business, public and commercial purpose) and recreational zone (sub-zone of urban parks, squares, gardens, boulevards). Snow dump sites $\mathrm{CO} 4$ and $\mathrm{CO} 2$ are situated in the production-business area (subzone of servicing facilities required for the implementation of production and business activities), and $\mathrm{CO} 3$ - in the recreational zone (sub-zone of city parks, squares, gardens, boulevards).

On the territory of the mentioned zones construction and expansion of operating industrial, communal and storage objects are not allowed except directly related to the operation of health and recreational, business, public and commercial objects [8]. Accordingly, there is a violation of the permitted types of land use of these ground areas which makes assessment of duration and negative impact level of snow dumps even more relevant.

Analysis of the satellite images in the period of 10 years allowed to exactly define that start of $\mathrm{CO} 1$ is 2013; $\mathrm{CO} 2-2007$; CO3-2010; CO4 - 2006. According to the existing images the borders of $\mathrm{CO} 3$ and $\mathrm{CO} 4$ for each year of work in the form of thematic layers of the digital map were constructed and they areas from the time of creation until 2015 were defined. On the figure 1, as an illustration, the images of snow dumps in the year of creation and in 2015 and their borders made on the base of these images was shown. 


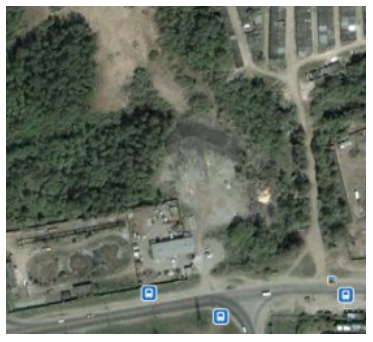

$\mathrm{CO} 4-2006$

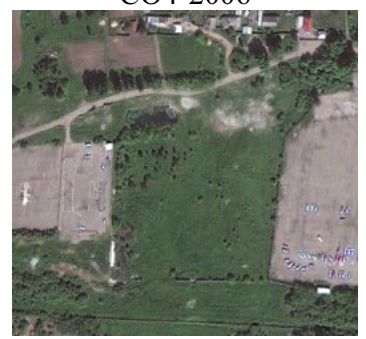

$\mathrm{CO} 3-2010$

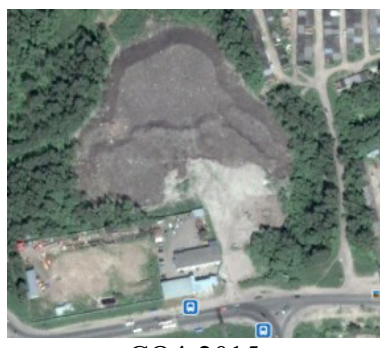

CO4-2015

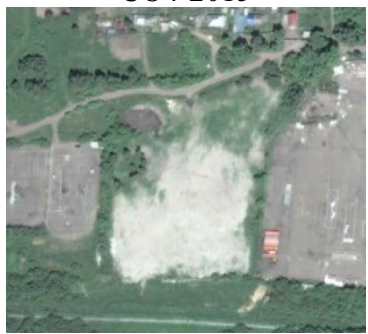

CO3-2015

Scale 1:10000

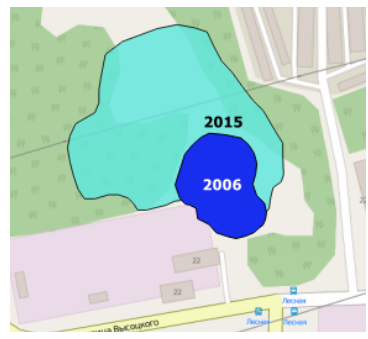

CO4-2006-2015

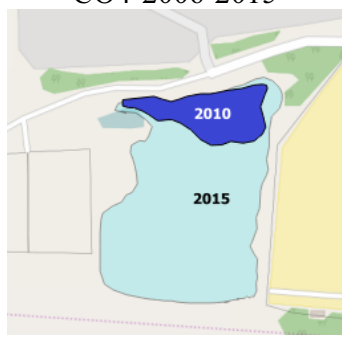

CO3-2010-2015

Figure 1. Satellite images and scheme of change of the snow dumps areas.

As it is shown in the figure 1 the territories of snow dumps are quite accurately decoded on the images of high spatial resolution indicated by degradation of vegetation cover especially in the autumnwinter period. Herewith the accuracy of tracing of the contour borders is very high and is situated in the limits of spatial resolution of the used image.

Analysis of dynamics of the snow dumps areas changes revealed a trend to increase of the area. Maximal growth was recorded for $\mathrm{CO} 3$ ( $+87 \%$ to the initial area). An average dynamics of the snow dump sites growth in Tomsk for the 10 years period is $18 \%$. Figure 2 shows a chart of snow dump CO3 change from 2009 till 2015 and forecast of development until 2017. It allows making a forecast for the nearest years. According to the chart the area CO3 increases approximately on $17 \%$.

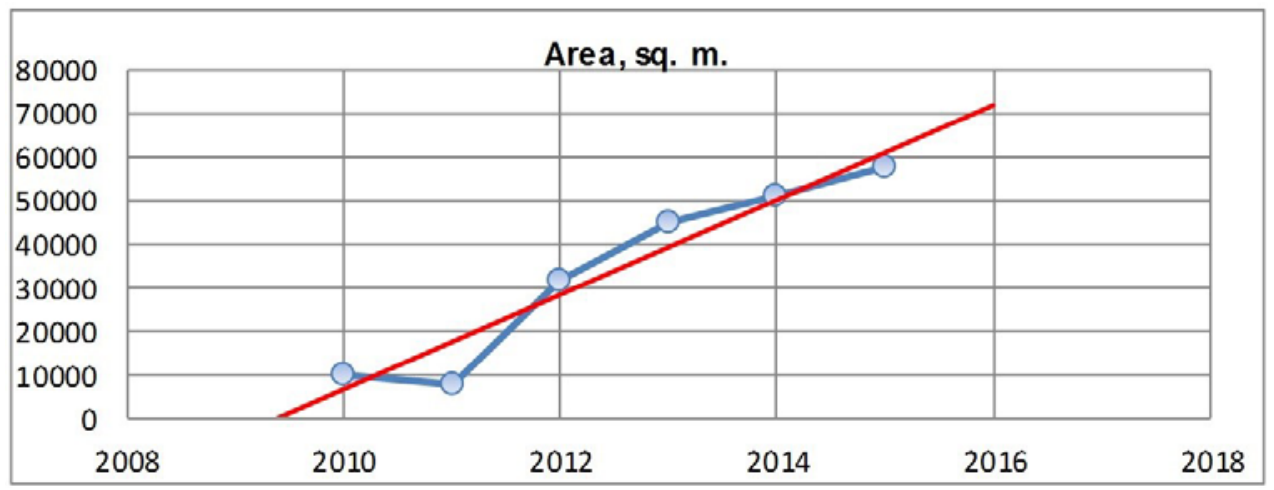

Figure 2. Forecast of the snow dump site $\mathrm{CO} 3$ area change.

Above it was stated that on the territory of snow dumps the degradation of vegetation which is not able to recover during the vegetation period was revealed. The most probable reasons may be:

- abnormally low temperatures of the soil in the beginning of vegetation period,

- $\quad$ excessive soil compaction by vehicles - dump trucks and bulldozers unloading and leveling of snow on a snow dump site;

- overwetting of the soil due to the long period of snow melting;

- soil contamination by the chemical reagents accumulated in the snow (exhaust gases etc.). 
For analyses of the soil temperature changes the temperature profiles were traced for $\mathrm{CO} 3$ and nearby background site (control) - in the center of sites with the protrusion of $10 \mathrm{~m}$. out of their borders from North to South. As it is shown on the figure 3, the character and dynamics of the profile temperature change on the snow dump and control site were significantly different. The temperature profile of the snow dump was characterized by the presence of an extremum. In the control it was absent. The difference between maximal and minimal temperatures in the frame of snow dump was in average $1,7^{\circ} \mathrm{C}$, in control $-0,4^{\circ} \mathrm{C}$. Approximately before the middle of May the central part of snow dump remained overcooled (on $2,5^{\circ} \mathrm{C}$, after its heating happened, and to the middle of June temperature was higher than the control on $4,3{ }^{\circ} \mathrm{C}$, to the end - on $5^{\circ} \mathrm{C}$ ). Inhibition of germination of plants by low temperatures in early stages affected their growth and development, which is planned to study in the future researches.

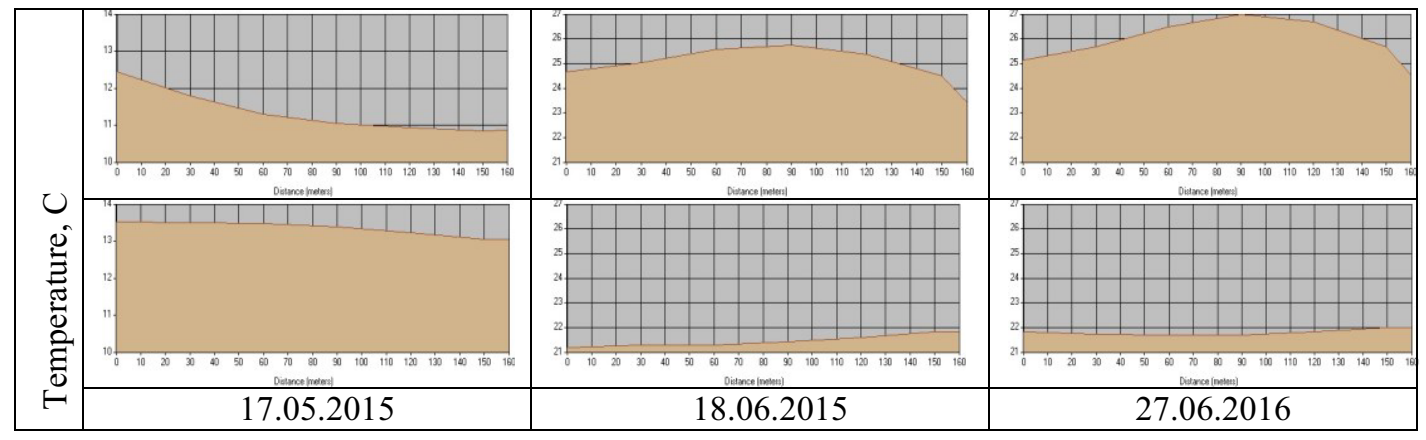

Figure 3. Temperature profiles for CO3 (upper row) and background site (the lower row) in May-June 2016.

\section{Conclusion}

The use of RSD allowed to obtain actual information about snow dump sites in Tomsk which was not possible to do by any other methods:

- allocation of snow dumps out of areas permitted for this type of the land use was defined;

- for the first time the time of snow dumps creation in Tomsk was revealed;

- the cartographic material, reflecting dynamics of snow dumps borders was collected;

- the trends of the snow dump sites' areas changes was analyzed and forecast of their changes in the nearest years was made;

- abnormal temperature regime on the snow dump sites was revealed.

The results obtained during the work may be initial material for perfection of snow dump site territory management and be applied in monitoring of environmental services for strengthening of environmental safety of the territory.

\section{References}

1. O. Pasko, T. Mochalova, IOP Conf. Ser.: Earth Environ. Sci. 21, 12044 (2014)

2. L. Altunina, L. Svarovskaya, Y. Polishchuk, O. Tokareva, Petr. Chem. 51, 381 (2011)

3. L. Feng, X. Han, C. Hu, X. Chen, Rem. Sens. Environment. 176, 43 (2016)

4. Weath. \& Clim. Electronic resource. URL: http://www.pogodaiklimat.ru/climate/29430.htm (2016)

5. GoogleEarth. Planet Earth for PC. Electronic resource. URL:http://www.google.com/earth/ (2016)

6. Urban atlas of Tomsk. Electronic resource. URL: http://map.admin.tomsk.ru/ (2016)

7. U.S. Geological Service. Electronic resource. URL: http://landsat.usgs.gov/landsat8.php (2016)

8. Urban zoning. Electronic resource. URL: http://www.zemvopros.ru/page_4603.htm (2016) 